\title{
Research on the Influence of Customer Perceived Value on Brand Equity
}

\author{
Bo Yan \\ School of Management, Jinan University, Guangzhou, China \\ Email: y anbo19910911@163.com
}

How to cite this paper: Yan, B. (2019) Research on the Influence of Customer Perceived Value on Brand Equity. American Journal of Industrial and Business Management, 9, 609-626. https://doi.org/10.4236/ajibm.2019.93042

Received: February 25, 2019

Accepted: March 19, 2019

Published: March 22, 2019

Copyright $\odot 2019$ by author(s) and Scientific Research Publishing Inc. This work is licensed under the Creative Commons Attribution International License (CC BY 4.0).

http://creativecommons.org/licenses/by/4.0/ (c) (i) Open Access

\begin{abstract}
As an important part of brand management, brand equity is being studied and concerned by more and more scholars and managers. The research of brand equity has experienced the change from the early stage of the company's financial angle of view to the customer's angle of view; this article is mainly from the latter. In the research of customer perceived value, predecessors mostly start from the perspective of functional and emotional value. The unique feature of this study is that it adds a cost perspective because the difference between what consumers get and what they pay constitutes the whole of perceived value. For customers, brand is in line with its closely linked value, and is the core factor of forming customer loyalty; for brands, customers are the foundation of brand survival and development. Customer perceived value is the direct experience in the process of consumption, which has a profound impact on consumers' brand evaluation. Therefore, this study takes the impact of customer perceived value on brand equity as a breakthrough point, and explores the impact of three dimensions of customer perceived value on brand equity. From the perspective of increasing cost in theory, this paper examines the meaning of customer perceived value, enriches the research on the influencing factors of brand equity, and puts forward suggestions for brand management and marketing strategies of Chinese enterprises in practice. In terms of research design and methodology, this study mainly takes smartphone brands at home and abroad as the research object, and tests the hypothesis of this paper through questionnaire survey. The analysis method mainly uses reliability, validity analysis and related analysis. The results show that functional value, emotional value and cost have positive effects on brand equity. At the same time, in the process of customer perceived value impact on brand equity, the relationship between the consumer and the brand continues has been deepened, and the enterprise's brand equity has been added. On this basis, Chinese enterprises should
\end{abstract}


change the traditional concept of brand management, under the new situation, consumers, and strive to improve customer perceived value, so as to create new development opportunities for the construction and management of brand equity.

\section{Keywords}

Customer Perceived Value, Brand Equity, Functional Value, Functional Value

\section{Introduction}

The continuous improvement of economic development level makes product homogeneity more and more serious, which makes the marketing cost of enterprises continue to grow. Managers have fully realized the role of brand in market competition. Brand equity has become the most important asset of enterprises, and its construction and management have been incorporated into the company's development strategy. Domestic and foreign scholars have recognized that brand equity is a complex, not a single element. Under the tide of global economic integration, Chinese local enterprises have begun to establish brand awareness with Chinese characteristics and make comprehensive use of brand strategy. Customer value refers to customer perceived value, which is the trade-off between perceived gain and perceived loss. Business operators have realized the importance of customer perceived value to customer satisfaction and loyalty in the process of practice. How to improve customer perceived value in the process of managing brand equity will directly affect customers' choice and evaluation of brand. Therefore, it is very important to incorporate customer perceived value into the construction of brand equity.

At present, the academic research on both of them is relatively mature, and a certain logical relationship has been established. These conclusions and understandings have laid the foundation for the further exploration of this paper, but after sorting out, the remaining research defects have also been found. Firstly, in the field of brand equity research, scholars focus more on the measurement of components and the specific value of assets, so there is a lack of research on the impact of customer perceived value on brand equity. Secondly, qualitative research is in the majority and quantitative research is lacking, so it is difficult to explain the relationship between variables from a quantitative point of view. Starting from the above problems, this paper intends to make a quantitative analysis of the two from the perspective of the impact of customer perceived value on brand equity; at the same time, it fills in the deficiencies of the existing empirical research, and further explores the logical relationship between variables based on the basic theory of consumer behavior, so as to provide suggestions for enterprises to better manage brand equity and deal with consum- 
er-brand relationship.

In the research method, this paper mainly adopts the combination of literature research and empirical research, lays the theoretical foundation for the research through literature reading and combing, and uses SPSS 20.0 and other data analysis and statistical software to quantify the survey data to verify the hypothesis proposed in this paper, the specific methods include reliability analysis, validity analysis, correlation analysis.

\section{Literature Review}

The following literature review will focus on the concept and composition of customer perceived value and the definition of brand equity. By reviewing and sorting out the existing research results and discussing the related concepts and theories, this paper draws a conclusion on the definition and components of customer perceived value and brand equity, which matches the theoretical model of this study.

\subsection{Customer Perceived Value}

\subsubsection{The Concept of Customer Perceived Value}

The research on "value" has a long history, which mainly involves the fields of economics and management. Ye et al. (2002) pointed out that the judgment and measurement of value will directly affect the behavior choice of relevant stakeholders [1]. In marketing, value refers to the benefits of the seller in the process of commodity trading, on the other hand, it can also refer to the gains of products or services obtained by the buyer in the transaction. This paper mainly elaborates the impact of perceived value on enterprise brand equity from the perspective of customers.

Foreign scholars define customer perceived value mainly as follows:

Monroe (1996) believes that the trade-off between the specific benefits and the specific losses that customers can perceive is customer perceived value. Among them, perceived benefits are entity characteristics, service characteristics and possible technical support related to the use of specific products. Perception losses involve various expenditures and potential costs associated with all consumer behavior [2]. In the conceptual interpretation of customer perceived value, Monroe lacks a clear expression of the connotation of perceived quality itself and how customers weigh perceived benefits against perceived losses.

Philip Kotler (2012) believes that the difference between total customer value and total customer cost is customer perceived value. Among them, the total customer value refers to a series of benefits that customers obtain from a particular commodity; the total customer cost refers to the time, energy and money costs generated by customers in the process of purchasing [3]. Customers often choose the products with the highest value and the lowest cost as the preferred object of purchase. Kotler's generalization of customer perceived value has been widely accepted by scholars. At the same time, his definition and description include the specific content of total value and total cost, and make a prediction of 
consumers' possible behavior choices.

In this study, customer perceived value is not a single value, but a synthesis of value. Through sorting out the research conclusions of the above scholars on customer perceived value, according to the content and research perspective of customer perceived value, this study will synthesize the two perspectives of customer and brand equity, and define customer perceived value as the gain and loss of value that consumers can specifically perceive through the actual contact process with brand in various situations. It is a comprehensive evaluation of the value delivered by customers to the brand. Customer perceived benefits include the perception of all kinds of value factors that can bring real benefits to consumers, including functional value and emotional value. Customer perceived loss is the perception of all kinds of factors that cause value loss to consumers, which can be understood as customer perceived cost, such as financial expenditure, time or emotional cost.

\subsubsection{Composition of Customer Perceived Value}

Based on the needs of this study and the definition of customer perceived value by scholars at home and abroad, this paper further refines the concept and generates specific indicators which are easy to quantify, thus deepening the understanding and explanation of the concept. In the current research, there are mainly the following kinds of subdivisions of customer perceived value components: customer perceived value, customer perceived value, customer perceived value, customer perceived value, customer perceived value, customer perceived value, customer perceived value, customer perceived value, customer perceived.

Parasuraman (2000) believes that the driving factors of customer value are general value, brand value and relationship value. Among them, the general value driving factors are composed of quality, price and convenience; the brand value driving factors are composed of customer brand awareness, customer brand identity and customer brand loyalty; and the relationship value driving factors are composed of emotional atmosphere, emotional connection and transfer cost [4].

Lapierre (2002) subdivides customer perceived value into different components, and uses empirical analysis method to transform the original qualitative analysis perspective into quantitative analysis perspective [5]. Lapierre makes a quantitative analysis of customer perceived value from three perspectives, and provides a new research entry point for exploring the influencing factors of customer perceived value.

Based on the previous research results of customer perceived value, this study concludes that two factors should be considered: 1) perceived benefits and perceived losses are the main components of customer perceived value; 2 ) the value provided by a brand to customers includes not only the physical properties of its products, but also the psychological effects [6]. Therefore, after synthesizing Lapierre's and Parasuraman's views on customer perceived value, this study concludes that customer perceived value consists of functional value, emotional 
value and customer cost. Based on the previous research results of customer perceived value, this study concludes that two factors should be considered: 1) perceived benefits and perceived losses are the main components of customer perceived value; 2 ) the value provided by a brand to customers includes not only the physical properties of its products, but also the psychological effects [6]. Therefore, after synthesizing Lapierre's and Parasuraman's views on customer perceived value, this study concludes that customer perceived value consists of functional value, emotional value and customer cost.

\subsubsection{Dimensions of Customer Perceived Value}

1) Functional value and emotional value

Holbrook divides the value types from three key dimensions: the external/internal value, the self-oriented/others-oriented value and the active/responsive value. In his definition, functional value is a kind of value that is self-centered and responsive, which is externalized as the physical attributes of products, emphasizing the brand's functional performance and the ability to solve a problem. Emotional value refers to the external means by which consumers can actively control their consumption behavior and respond to their demands in a timely and effective manner. It is a value expression produced by customers subjectively and centered on objective reflection. Emotional value arises from non-product attribute association, which involves the overall image of the brand users, and reflects the potential needs of social identity, self-expression, communication and self-esteem. In the customer perceived value studied in this paper, functional value involves a person's need for effective management of his physical environment; emotional value involves a person's need for effective management of his psychological environment. These two factors constitute the main part of customer perceived value gains, and play an important role in consumer purchasing behavior.

2) Cost

The cost of financial expenditure is the monetary embodiment that consumers pay in order to obtain the interests related to their needs. For consumers, it is the price of products. Therefore, the monetary cost is the most intuitive cost that customers can feel immediately in the process of consumption [7]. The cost of time and energy is the time and energy consumed by customers in purchasing products. The emotional cost is the personal feelings that consumers pour into in order to obtain a specific product or service. Time, energy and emotion belong to consumers' non-financial expenditure costs, which are negatively related to customer satisfaction.

\subsection{Brand Equity}

\section{Definition of Brand Equity}

At present, domestic and foreign scholars generally define brand equity from two perspectives: one is from the financial revenue level or market share level of enterprises to define and measure brand equity; the other is from the customer's 
perception of the brand or the relationship between customers and brands. The first kind of research focuses on the financial benefits that brand as an intangible asset can bring to the company's operation, which also becomes the monetary price that competitors in the same industry need to pay when they imitate the brand. The second perspective summarizes brand equity from a customer-based perspective, focusing on the impact of purchasing behavior choice on the value of brand equity [8]. The impact of customer perceived value on brand equity explored in this paper is mainly from the cognitive perspective of customer level.

David A. Aaker (1991) believes that brand equity is a combination of brand equity and liabilities related to brand, name and logo. It can increase or decrease the value of products or services provided to companies or their customers. From the customer's point of view, brand equity is the value of the brand in the eyes of target groups [9]. According to the above judgments, he put forward five-star model of brand equity, which includes: 1) brand loyalty; 2) brand awareness; 3) perceived quality; 4) brand association; 5) other brand equity. Aaker's model takes into account both brand value evaluation and brand equity measurement, and modularizes the composition of brand equity. The understanding and application of these five elements will directly affect the operational efficiency of enterprise brand equity. How to improve the positive perception of the constituent factors also affects consumers' understanding of brand value.

Keller puts forward the concept of customer-based brand equity and defines it as a psychological differential reflection of corporate brand marketing caused by consumer brand knowledge. He proposed that customer's brand knowledge includes two dimensions: brand awareness and brand image, and generalized brand attributes as product-related attributes and non-product-related attributes. The benefits of brand for customers include functional benefits, empirical benefits and symbolic benefits. Among the non-product related attributes, users and uses, feelings and experiences, brand personality have already involved customer emotional feedback, and symbolic interests reflect the potential needs of social identity, self-expression and communication and self-esteem. Keller's brand knowledge theory mainly discusses the components of brand equity from the customer's point of view, makes a comprehensive and scientific study of the links between the elements involved in the theoretical model, and designs a detailed process to verify the feasibility of the theory, so that the whole theoretical system is rigorous and logical. In practice, it also provides theoretical guidance for enterprises on how to create and manage brand equity efficiently.

Domestic scholars have the following views on the research of brand equity: Fan Xiucheng (2002) believes that brand equity is the added value of products or services given by enterprises in the past marketing efforts on brand. At the same time, he has done the research on brand equity from three aspects: finance, customers and extended benefits [10].

Further subdivision. Zhou Zhimin and Lu Taihong (2004) focused on the value evaluation of brand equity, and reviewed the main quantitative evaluation 
methods at home and abroad [11]. Wei Haiying and Wang Guiming analyzed the elements of brand equity and extracted the five most important elements of brand equity for the first time.

From the quantitative point of view, the most important factor of brand equity is brand status and customer value orientation, and according to the constituent factors of brand equity, the types of brand equity are classified [12].

Although scholars have different opinions on the related statements of brand equity, there are three points in common: 1) brand equity is an intangible asset; 2) brand equity is generated by relying on the brand;3) the value of brand equity to the brand owner is generated through the impact on customers [13]. At present, the research on brand equity is also focused on the measurement of brand equity with customers as the core and the analysis of its components. The customer-based brand equity can reveal the driving factors hidden behind the economic value of brand equity, which has important guiding significance for enterprise brand management decision-making. Based on the above literature on brand equity and customer perceived value, a comparatively perfect study has been made on the constituent factors of both, but there is still no clear research on the correlation between each factor and causality to elaborate the corresponding conclusions. According to the research needs, this paper defines customer-based brand equity as an intangible asset, which is caused by the customer's different reaction to the enterprise's marketing activities in the aspects of cognition, emotion, attitude and behavior. Meanwhile, in the five-star model of brand equity proposed by Aaker, brand loyalty, brand awareness, perceived quality and brand association are the four most adopted elements. Therefore, this study will mainly analyze the impact of customer perceived value on brand equity from these four aspects.

\section{Research Hypothesis and Theoretical Model}

\subsection{The Theoretical Basis of Consumer Behavior}

Consumer Behavior is a science that studies consumers' purchase psychology and behavior choice. It has important guiding significance for marketing practice under the concept of customer-oriented marketing [14]. Paul Peter (2000), Li (2004) believes that the dynamic process of cognition, perception, behavior and environmental factors is the behavioral basis for human beings to fulfill their trading functions in life [15]. Cognition is a process in which an individual reacts to the external environment; perception refers to people's personal experience and feelings; behavior refers to specific external activities that consumers can observe directly; environment includes a combination of natural and social stimulating factors to consumers. There is a hierarchical and logical relationship among cognition, perception, behavior and environment to some extent: perception and cognition are two different types of psychological reflection that consumers can produce when they buy goods, perception is the subjective impression and reaction of consumers to products or services, while cognition re- 
lies more on consumers' rational judgment. Both of them will affect behavior, leading to the emergence or change of behavior. Behavior outcomes in turn affect the degree of consumer perception and cognition, while the environment will affect the first three from various external aspects [16]. This theory describes the process of consumer behavior and makes a more rigorous logical analysis. The choice and implementation of consumer buying behavior is to a large extent only a reflection of consumers' real attitude. True loyalty comes from consumers' inner attitude towards brand, which will affect customers' purchasing under more complex conditions. By analogizing the process of consumer behavior to the effect of customer perceived value on brand equity, it is concluded that customer's perception of functional and emotional value will affect the perceived quality of brand equity; and the actual value of brand passed to consumers is related to brand awareness and consumers' association with brand; finally, as the behavior and attitude caused by customer perceived value. The result is brand loyalty. This study is based on the basic content of the theory to carry out follow-up discussion, from the deep-seated causes of consumer behavior to explore customer value and brand equity. At the same time, for the research of this topic, the impact of environmental factors is bound to exist. Considering the breadth and depth of individual academic ability and research, this study will not include environmental factors in the scope of research for the time being.

\subsection{Research Hypothesis}

\subsubsection{Functional Value and Brand Equity}

Functional value mainly depends on the physical attributes of products or services [17], emphasizing the brand's function performance and the ability to solve certain problems, which can meet the physiological and safety needs of consumers, and attaching importance to the practicability and means of objects and experiences. Customer's Sense of Functional Value of Products Knowledge is the most direct and obvious. Therefore, the higher the degree of value perception, the more positive customer perception of the brand quality can be strengthened, brand awareness can be enhanced, which is conducive to promoting the formation and strengthening of brand loyalty and building positive brand association. To this end, this paper makes the following assumptions:

$\mathrm{H} 1$ : Customer's functional value is positively correlated with brand equity.

H1a: Customer's functional value is positively correlated with perceived quality.

H1b: Customer's functional value has a positive impact on brand awareness.

H1c: Customer's functional value has a positive impact on brand loyalty.

H1d: Customer's functional value is positively correlated with brand association.

\subsubsection{Emotional Value and Brand Equity}

Emotional value arises from non-product attribute association [18], which involves the overall image of the brand users, and reflects the potential needs of 
social identity, self-expression, communication and self-esteem. The unique "face" culture in China vividly depicts the emotional value experience of customers in the process of consumption. Customers are no longer confined to physiological satisfaction when consuming a product or service, but want more positive comments from others. Therefore, consumer's emotional value perception can effectively increase the understanding of brand recognition, and the perception of brand quality can go beyond the level of physiological needs satisfaction and then go deep into the level of consumers' mind. Faced with the increasingly serious market situation of product homogeneity, building brand's unique advantages in consumer emotions is conducive to enhancing brand identification, thus cultivating and stabilizing consumer brand loyalty and generating unique brand association. To this end, this paper makes the following assumptions:

H2: Customer's Emotional Value and Brand Equity are positively correlated.

$\mathrm{H} 2 \mathrm{a}$ : Customer's emotional value is positively correlated with perceived quality.

$\mathrm{H} 2 \mathrm{~b}$ : Customer's emotional value has a positive impact on brand awareness.

H2c: Customer's emotional value has a positive impact on brand loyalty.

$\mathrm{H} 2 \mathrm{~d}$ : Customer's emotional value is positively correlated with brand association.

\subsubsection{Cost and Brand Equity}

Customer perceived value $(\mathrm{CPV})$ is a comparative evaluation of the gains and losses generated by consumers' purchasing behavior. The specific gains and losses are mainly reflected in the payment of money, time, emotion and so on. The increase of financial cost will aggravate consumers' pain, reduce satisfaction and weaken brand value. The increase of time cost will delay the completion of consumer behavior, increase the uncertainty of transaction, and make the customer's concept of brand obscure. Increased emotional costs can drain customers Passion for brand and patience will eventually lead to the breakdown of Customer-Brand relationship. To this end, this paper makes the following assumptions:

H3: Negative correlation between customer cost and brand equity.

$\mathrm{H} 3 \mathrm{a}$ : Customer's cost is negatively correlated with perceived quality.

$\mathrm{H} 3 \mathrm{~b}$ : Customer's cost is negatively correlated with brand awareness.

$\mathrm{H} 3 \mathrm{c}$ : Customer's cost is negatively correlated with brand loyalty.

H3d: Customer's cost is negatively correlated with brand association.

\subsection{Research Model}

Based on the above theoretical basis and assumptions, this paper makes the following theoretical models (showing in Figure 1).

\subsection{Questionnaire Design}

The questionnaire of this study mainly focuses on the existing smartphone brands, mainly because the popularity of smartphones makes the consumer 


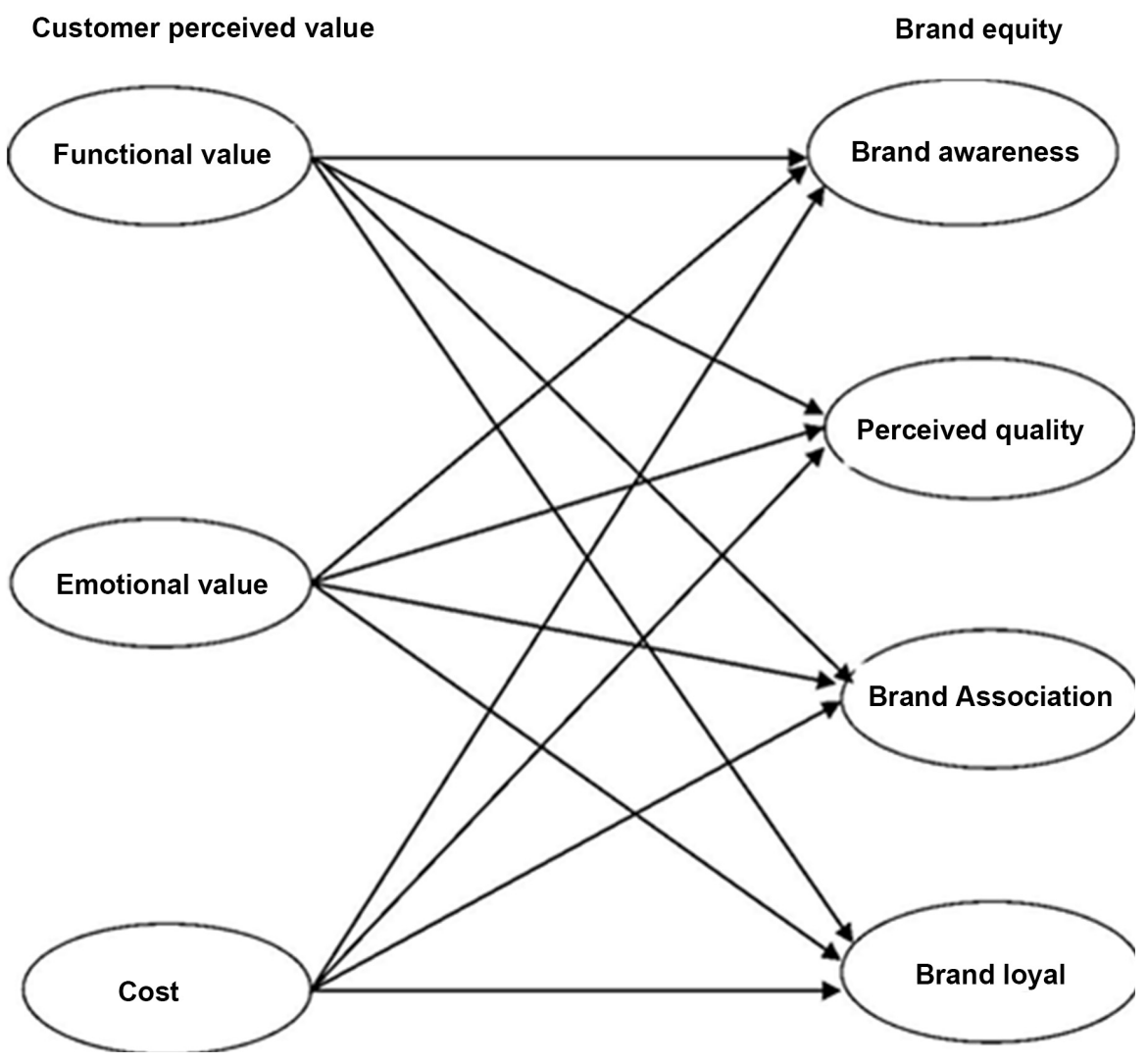

Figure 1. Research model.

groups have a certain extent of universality and representativeness, so the survey data is relatively objective and convincing. The questionnaire consists of two parts. The first part is the basic information, and the second part is about the two scales. The research mainly involves seven dimensions: functional value, emotional value, cost, perceived quality, brand awareness, brand association and brand loyalty.

\subsection{Content of the Scale}

In terms of customer perceived value, functional value and emotional value mainly refer to Lapierre and Jillian scales, while cost refers to Jillian and Geoffrey scales [13]. Finally, according to the relevant needs of this study, the above scales are revised to conform to this study. Questions on research. As for the brand equity scale, the brand awareness scale is composed of Aaker, Keller and Yoo scales. The perceived quality scale was synthesized by Yoo and Netemeyer, and the brand association scale by Keller (1993). The scale of Yoo (2001), Netemeyer (2004) concludes that the scale of brand loyalty is composed of Griffm (1995), Fournier (2001). Yoo (2001) Attitude Loyalty Scale. Therefore, the questionnaire in this study is based on the combination of the above relatively mature scales. After studying the specific situation, it became the basis of the questionnaire. 


\section{Data Statistics and Analysis}

\subsection{Descriptive Analysis}

The sample of this survey mainly focuses on College students, among which $42.72 \%$ are boys and $57.28 \%$ are girls; $65.53 \%$ are aged from 16 to $24,16.99 \%$ are aged from 25 to $35 ; 30.58 \%$ are within 1000 yuan per month, which shows that most of the respondents may be students, $16.5 \%$ are from 1000 to 1500 yuan, and the rest of the income ranges are more uniform. Uniform, mainly concentrated in about $13 \%-14 \%$, Apple accounted for $37.38 \%$, millet accounted for $17.96 \%$, Huawei accounted for $11.17 \%$, Samsung and Meizu accounted for the same proportion. The remaining brands account for a small number; the price statistics of purchasing machines are mainly concentrated in the range of more than 3000 yuan, accounting for about 35.92\%, 1500 - 2000 yuan accounted for $19.9 \%$. Among them, the proportion of $1000-1500$ yuan is about $13.59 \%$, and that of less than 1000 yuan is about $12.14 \%$. In terms of mobile phone use time, the proportion of 6 months to 1 year is the largest, accounting for $31.07 \%$, and that of $1-2$ years is about $26.7 \%$.

\subsection{Reliability and Validity Test of Scale}

The purpose of reliability analysis of the scale is to test the matching degree between the various items of the scale and the stability of the test results. Scale validity analysis is designed to test the measurement dimension designed to reflect the authenticity of the content measured. Higher reliability and validity indicators can better measure the reliability and authenticity of research questionnaires. At the same time, reliability and validity test is an indispensable part of empirical research. They are directly related to the accuracy and effectiveness of quantitative analysis. Cronbach's alpha coefficient was used to analyze the reliability of this study. If Cronbach's alpha is greater than 0.9 , the internal reliability of the scale is considered to be high; if Cronbach's alpha is greater than 0.8 (less than 0.9 ), the internal reliability is acceptable; if Cronbach's alpha is greater than 0.7 (less than 0.8), the design of the scale is considered to be problematic, but it can be used as a reference. Value. If Cronbach's alpha is less than 0.7 , it is considered that there are major problems in the design of the scale that needs to be modified. The validity of the scale was tested by the standardized factor load coefficient, which was greater than 0.5 , indicating the validity of the scale.

\subsubsection{Reliability Analysis}

The reliability test results are shown in Table 1 below. The Cronbach's Alpha coefficient of the overall scale is 0.962 , which indicates that the scale is trustworthy. Among them, the Cronbach's Alpha value of customer perceived value (B1-B12) is 0.902, and the Cronbach's Alpha value of brand equity (C1-C16) is 0.956, which all meet the measurement requirements shown in Table 2. Therefore, it is believed that the scale has good reliability and its reliability test has passed. 
Table 1. Reliability analysis.

\begin{tabular}{|c|c|c|c|c|c|c|c|}
\hline Item & $\begin{array}{c}\text { Corrected } \\
\text { Item-Toal } \\
\text { Correlation }\end{array}$ & $\begin{array}{l}\text { Cronbach's alpha if } \\
\text { Item Deleted }\end{array}$ & $\begin{array}{l}\text { Cronbach's } \\
\text { alpha }\end{array}$ & Item & $\begin{array}{c}\text { Corrected } \\
\text { Item-Toal } \\
\text { Correlation }\end{array}$ & $\begin{array}{l}\text { Cronbach's alpha if } \\
\text { Item Deleted }\end{array}$ & Cronbach's alpha \\
\hline B1 & 0.795 & 0.788 & \multirow{4}{*}{0.860} & $\mathrm{C} 1$ & 0.681 & 0.814 & \multirow{5}{*}{0.843} \\
\hline B2 & 0.682 & 0.852 & & $\mathrm{C} 2$ & 0.677 & 0.807 & \\
\hline B3 & 0.722 & 0.816 & & C3 & 0.761 & 0.766 & \\
\hline B4 & 0.691 & 0.827 & & $\mathrm{C} 4$ & 0.654 & 0.815 & \\
\hline B5 & 0.665 & 0.857 & \multirow{4}{*}{0.870} & C5 & 0.844 & 0.859 & \\
\hline B6 & 0.781 & 0.809 & & C6 & 0.790 & 0.879 & \multirow{3}{*}{0.906} \\
\hline B7 & 0.802 & 0.800 & & C7 & 0.742 & 0.894 & \\
\hline B8 & 0.654 & 0.860 & & $\mathrm{C} 8$ & 0.788 & 0.879 & \\
\hline B9 & 0.690 & 0.786 & \multirow{4}{*}{0.838} & C9 & 0.829 & 0.835 & \multirow{4}{*}{0.891} \\
\hline B10 & 0.503 & 0.873 & & $\mathrm{C} 10$ & 0.757 & 0.861 & \\
\hline B11 & 0.751 & 0.761 & & $\mathrm{C} 11$ & 0.787 & 0.850 & \\
\hline B12 & 0.764 & 0.751 & & $\mathrm{C} 12$ & 0.679 & 0.893 & \\
\hline B1-B12 & - & - & 0.902 & $\mathrm{C} 13$ & 0.726 & 0.780 & \multirow{4}{*}{0.843} \\
\hline- & - & - & - & $\mathrm{C} 14$ & 0.740 & 0.774 & \\
\hline - & - & - & - & $\mathrm{C} 15$ & 0.692 & 0.798 & \\
\hline- & - & - & - & $\mathrm{C} 16$ & 0.576 & 0.844 & \\
\hline B1-C16 & - & - & 0.962 & $\mathrm{C} 1-\mathrm{C} 16$ & - & - & 0.956 \\
\hline
\end{tabular}

Table 2. Validity analysis.

\begin{tabular}{ccccccccc}
\hline & KMO & Bartlett's & Sig. & & KMO & Bartlett's & Sig. \\
\hline Functional value & 0.813 & 380.412 & 0.000 & Brand awareness & 0.817 & 346.423 & 0.000 \\
Emotional Value & 0.777 & 425.734 & 0.000 & Perceived quality & 0.826 & 536.693 & 0.000 \\
Cost & 0.765 & 385.013 & 0.000 & Brand Association & 0.809 & 496.973 & 0.000 \\
& & & & Brand loyalty & 0.787 & 340.209 & 0.000 \\
\hline
\end{tabular}

\subsubsection{Validity Analysis}

From the data analysis of Table 3, it can be concluded that KMO values of three measurement dimensions of customer perceived value and four dimensions of brand equity are all greater than 0.7 and Sig are all 0.000 , which indicates that this study is suitable for factor analysis.

\subsection{Hypothesis Test Analysis}

There are three main analysis paths in this paper. Brand equity is divided into four aspects: brand awareness, perceived quality, brand association and brand loyalty. Functional value (path A1-A4), emotional value (path B1-B4) and cost (path C1-C4) are tested respectively. The influence of factors on brand equity. Therefore, there are three hypotheses, and four subdivision hypotheses are set under each hypothesis. 
Table 3. The relevance coefficient and significance of the relationship between customer perceived value and brand equity.

\begin{tabular}{cccccc}
\hline Item & & $\begin{array}{c}\text { Brand } \\
\text { awareness }\end{array}$ & $\begin{array}{c}\text { Perceived } \\
\text { quality }\end{array}$ & $\begin{array}{c}\text { Brand } \\
\text { association }\end{array}$ & Brand loyalty \\
\hline Functional value & Relevance & $0.589^{* *}$ & $0.589^{* *}$ & $0.589^{* *}$ & $0.589^{* *}$ \\
& Saliency & 0.000 & 0.000 & 0.000 & 0.000 \\
Emotional value & Relevance & $0.639^{* *}$ & $0.695^{* *}$ & $0.701^{* *}$ & $0.700^{* *}$ \\
& Saliency & 0.000 & 0.000 & 0.000 & 0.000 \\
Cost & Relevance & $0.440^{* *}$ & $0.437^{* *}$ & $0.499^{* *}$ & $0.462^{* *}$ \\
& Saliency & 0.000 & 0.000 & 0.000 & 0.000 \\
\hline
\end{tabular}

According to the correlation coefficient between customer perceived value and brand equity and its significance analysis data, the correlation coefficient between "functional value" and "brand awareness" is 0.589 , and shows a significant positive correlation. The data show that functional value has a greater positive impact on brand awareness; the correlation coefficient between "functional value" and "perceived quality" is 0.650 . Therefore, functional value has a significant positive impact on perceived quality; "functional value" and "brand association" correlation coefficient is 0.658 , the former has a significant positive impact on the latter; "functional value" and "brand loyalty" correlation coefficient is 0.633 , indicating that functional value has a positive impact on brand. There is a significant positive correlation between loyalty. Considering the impact of customer perceived value on each dimension, the hypothesis H1a, H1b, H1c and $\mathrm{H} 1 \mathrm{~d}$ are validated, and thus $\mathrm{H} 1$ is validated, that is, functional value has a significant positive impact on brand equity.

Similarly, from the above table, we know that the correlation coefficient between "emotional value" and "brand awareness" is 0.639 , which has a significant positive correlation, so we can conclude that emotional value has a strong positive impact on brand awareness; the correlation coefficient between "emotional value" and "perceived quality" is 0.695 , which shows that emotional value has a significant positive impact on perceived quality; and "emotional value" has a significant positive impact on perceived quality. "The correlation coefficient" with "brand association" is 0.701 , the former has a significant positive impact on the latter; the correlation coefficient between "emotional value" and "brand loyalty" is 0.700 , so it is considered that the influence of emotional value on brand loyalty is positive and significant. According to the results of affective value's influence on four factors of brand equity, it is assumed that H2a, H2b, $\mathrm{H} 2 \mathrm{c}$ and $\mathrm{H} 2 \mathrm{~d}$ are validated, thus $\mathrm{H} 2$ is validated, that is, affective value has a significant positive impact on brand equity.

The correlation coefficient between "cost" and "brand awareness" is 0.440 , showing a positive correlation; the correlation coefficient between "cost" and "perceived quality" is 0.437 , indicating a significant positive correlation between cost and perceived quality; the correlation coefficient between "cost" and "brand association" is 0.499 , showing a significant positive impact; the correlation coef- 
ficient between "cost" and "brand loyalty" is 0.462 , so it is considered that the correlation coefficient between "cost" and "brand loyalty" is 0.462 . Cost has a positive impact on brand loyalty. Comprehensive analysis of the impact of customer costs on the four components of brand equity, the results of each correlation coefficient do not support the assumptions H3a, H3b, H3c, H3d established above. So the hypothesis that $\mathrm{H} 3$ cannot be verified, that is, the hypothesis that customer's cost is negatively related to brand equity is not valid.

\section{The Influence of Customer Perceived Value on Brand Equity}

\subsection{The Influence of Functional Value on Brand Equity}

From the above data analysis, we can see that functional value has a significant positive impact on brand equity. The more functional value a customer obtains in the process of consumption, the more favorable it will be to enhance the customer's preference for products and brands. Positive brand image and good word-of-mouth will further help to enhance the brand's popularity and reputation in the market, enrich the positive functional associations established by customers with brands, and promote consumers under the lasting and systematic customer relationship management. Form loyalty in choosing and purchasing behavior, and strive to deepen brand influence, dig deep into the guiding factors behind consumer behavior, so that brand loyalty is not only reflected in the level of behavior, but also more consistent with consumers' attitudes and tendencies, and ultimately establish a high-quality and powerful enterprise. Brand equity helps. Faced with the fierce competition in the market, customers can optimize their consumption experience by upgrading their products or services. In terms of functional value, we should pay attention to the innovation of products and services. Practice has proved that only continuous innovation can make the brand and service of enterprises. Only by maintaining the vitality and attractiveness of the market supply, can we maintain the position of not being eliminated in the changing industry and market shuffling, and thus take the lead in the competition with similar products in the market. All competitions are based on excellent product or service quality and are out of jail. Depending on the quality of hardware, all concepts will not be able to stand on. Therefore, it is the purpose of enterprises to continuously improve customers' perception of functional value.

\subsection{The Influence of Emotional Value on Brand Equity}

The positive correlation between emotional value and brand equity is very significant. This conclusion also reminds managers to change their traditional marketing concepts and brand management methods. From the primary stage of satisfying consumers' physiological needs to the harmonious co-construction with consumers' psychological and emotional levels. The rise of relationship marketing has changed the traditional marketing thinking and mode. Competition limited to $4 \mathrm{P}$ stage has been unable to adapt to the demands based on con- 
sumers' minds. Consumers' demand for products has gradually penetrated into the demand for brands, and they expect to realize the value expression of "ego" by means of the symbolic language conveyed by brands. The continuous improvement of the level of economic development has created a new generation of consumers with brand-new consumption concepts and purchasing behavior. They pay more attention to the value communication function of brand, pay more attention to the unity of individual expression and group mainstream values, and seek the sense of self-existence in various social organizations to achieve self-improvement. In this regard, the management of consumer-brand relationship must be timely updated to break through the old pattern and restrictions. The improvement of brand relationship quality depends not only on the value that the brand conveys to consumers, but also on the frequent and effective interaction with consumers to realize the connection and dependence between the two sides. With the help of intimate feelings between consumers and brands, the two sides will evolve into partners. In short, the management of consumer-brand relationship should be based on high-quality product and service, emotional connection as a link, common expression as a medium, and the optimization of brand equity as a goal.

\subsection{The Influence of Cost on Brand Equity}

Cost is the part that consumers pay in the process of consumption. To some extent, it causes consumer pain. On the other hand, under the unique "face" cultural background in China, "only buy expensive but not buy right" also reflects to some extent the growth of consumption costs to consumers. A pleasant experience. Through the perfect after-sales service mechanism and product performance to convince consumers to accept the premium part of goods, through psychological and emotional bonding to make up for the pain caused by increased customer costs. Customer cost also reflects all the costs of brand transfer. Therefore, the higher the cost, the more customers will cherish the connection with the existing brand and try to fill in the revenue of brand transfer by increasing the benefits they get from the existing brand. To a certain extent, this also deepens consumer loyalty to brand behavior and attitude. High customer satisfaction is the basis of customer loyalty. The key to maintaining customer loyalty is the sustained satisfaction of the brand. Transforming customer loyalty into intangible assets is brand capital. The constant pursuit of production construction management. At the same time, relatively high customer cost expenditure must be equipped with perfect brand service mechanism and high-quality product performance as an important compensation measure to establish customer brand loyalty. Only in this way can we effectively promote the continuous optimization of enterprise brand equity.

\section{Conclusion and Prospect}

\subsection{Main Conclusion}

According to the above research results, functional value has a significant posi- 
tive impact on all dimensions of brand equity; the relationship between emotional value and brand equity is a significantly positive correlation, while the impact of emotional value on the four components of brand equity is more significant. This also reflects the change of consumer behavior and value transfer of contemporary consumers. In response to this discovery, business managers need to change the old brand management concepts and methods, adjust the mechanism of affective value on brand equity; cost also has a positive correlation with brand equity. The more the customers pay for the brand, the more beneficial it is to strengthen the connection with the brand, thus increasing the cost of brand transfer. But when using the cost factor to bind the stickiness of consumers, we must be able to make up for the impact of perceived gains and losses from other aspects based on consumers' more perceived gains.

\subsection{Research Limitations and Prospects}

\subsubsection{Research Limitations}

There are still many deficiencies in the content and method of this study. First, due to the limitation of my academic research ability and the limitation of collation and understanding of past research materials, the understanding and statement of customer perceived value and brand equity are one-sided and lack of more comprehensive discussion; second, the impact model of customer perceived value on brand equity proposed in this paper is too simple and can be further explored if conditions permit. The influence of intermediate variables is considered. Thirdly, the research in this paper is one-sided. The main body of the research is mainly concentrate in College students, which does not have the universality and representativeness of the audience. The target market only aims at the smartphone market, but is not convincing to the situation of other types of products or services market. In the follow-up study, we can try to explore a wider range of target groups and user markets, in order to better apply the conclusion of the impact of customer perceived value on brand equity to business management practice.

\subsubsection{Future Prospects}

Brand relationship, as an important factor that may have an impact on both customer perceived value and brand equity, has gradually come into the vision of researchers and managers today when relationship marketing is prevalent. New customer relationship management inevitably requires enterprises to better handle the relationship between customers and brands, and create unique advantages in customer acquisition and customer retention. Therefore, future research can fully incorporate the role of brand relationship mechanism, in-depth study of the logical relationship between the three, and make greater contributions to the management of brand equity in practice. Finally, the value dissemination mechanism and means of brand equity may become a new perspective in the field of brand research. The information asymmetry between buyers and sellers is being reversed. Consumers are more and more actively participating in 
the design and development of products and services. Various new information media are infiltrating into them with unprecedented breadth and depth. The connection between customers and enterprises will not only be reflected in the terminal of sales and transactions, but also be transferred upstream to the supply chain as far as possible. Therefore, how to play the role of new media in brand equity shaping and value dissemination, and how to use the advantages of new media to enhance customer perceived value in an all-round way will become a topic worthy of further exploration in relevant research fields.

\section{Conflicts of Interest}

The author declares no conflicts of interest regarding the publication of this paper.

\section{References}

[1] Ye, S.H. and Wang, C.H. (2002) Development Analysis of Customer Value Theory and Its Enlightenment to Practice. Value Engineering, 4, 24-28.

[2] Moore, J.F. (1996) The Death of Competition. Arts \& Licensing International, New York, 12-17.

[3] Kotler, P. (2012) Marketing Management. 14th Edition, Shanghai People's Publishing House, Shanghai, 125.

[4] Parasuraman, A. and Grewal, D. (2000) The Impact of Technology on the Quality-Value-Loyalty Chain: A Research Agenda. Journal of the Academy of Marketing Science, 28, 168. https://doi.org/10.1177/0092070300281015

[5] Lapierre, J. (2013) Customer-Perceived Value in Industrial Contexts. Journal of Business \& Industrial Marketing, 15, 122-145. https://doi.org/10.1108/08858620010316831

[6] Lee, Y.K., Kim, S.Y., Chung, N., et al. (2016) When Social Media Met Commerce: A Model of Perceived Customer Value in Group-Buying. Journal of Services Marketing, 30, 398-410. https://doi.org/10.1108/JSM-04-2014-0129

[7] Zou, D.Q., Wang, G. and Zhao, P. (2007) The Influence of Functional Value and Symbolic Value on Brand Loyalty: The Moderating Role of Gender Differences and Brand Differences. Nankai Management Review, 3, 4-12.

[8] Zhou, Z.M. and Lu, T.H. (2004) Research on the Structure of Broad Brand Relations. China's Industrial Economy, 15, 98-105.

[9] Aaker, D.A. (1991) Managing Brand Equity: Capitalizing on the Value of a Brand Name. Free Press, New York, 411-423.

[10] Fan, X.C. (2000) Analysis of Brand Equity and Evaluation System. Nankai Management Review, 10, 9-15.

[11] Zhou, Z.M. and Lu, T.H. (2004) Research on the Structure of Broad Brand Relations. China's Industrial Economy, 15, 98-105.

[12] Wei, H.Y. and Wang, G.M. (2003) Key Factors and Types of Brand Equity Composition. Forecast, 22, 32-35.

[13] Wan, H.F. and Zhou, J.J. (2004) Brand Management. Tsinghua University Press, Beijing.

[14] Zeithaml, V.A. (1988) Consumer Perceptions of Price, Quality and Value: A 
Means-End Model and Synthesis of Evidence. Journal of Marketing, 52, 2-22. https://doi.org/10.1177/002224298805200302

[15] Paul Peter, J. and Olson, J.C. (2000) Consumer Behavior and Marketing Strategy. Translated by Han Dechang. Northeast Finance and Economics Publishing House, Dalian.

[16] Li, K.Q. (2004) Customer Value Advantage. Economic Science Publishing House, Beijing, 42.

[17] Aaker, J., Fournier, S. and Adam, B.S. (2008) When Good Brands Do Bad. Journal of Consumer Research, 1, 1-14.

[18] Fan, X.C., Bai, C.H. and Gan, Y. (2002) Brand Management of Service Enterprises Based on Customer Perceived Value. Foreign Economy and Management, 9, 7-11. 